Results 87 patients (82 females) had mean age 29.23 $\pm 13.13 \mathrm{SD}(6-62)$ at TB infection, mean SLE disease dura-

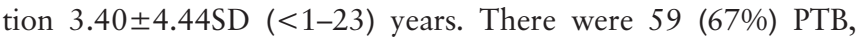
5 (6\%) EPTB, 23 (27\%) DTB. Extra-pulmonary sites included 8 meningitis or brain abscess, 7 soft tissue abscess, 7 pleural effusion, 3 genitourinary, 3 arthritis, 1 hepatobiliary, 1 ileocecal, 1 cutaneous. Average SLEDAI score was 4.74 \pm 3.19 SD $(0$ - 14), nephritis in 31 (35.63\%). Average cumulative prednisone was $15.29 \pm 19.38 \mathrm{SD}(0.5-86.4)$ grams; mean daily prednisone was $13.87+10.5 \mathrm{SD} \mathrm{mg}(0-50)$ with 22 patients (25.29\%) taking immunosuppressives 3 months preceding TB. Significant risks for DTB were nephritis $(p=0.017)$ and prednisone $>11 \mathrm{mg} / \mathrm{d}(\mathrm{p}<0.05)$. Sixty three $(72.41 \%)$ successfully completed anti-TB treatment. Among 24 deaths, 9 were attributed to TB (6 disseminated, 3 PTB respiratory failure), 15 due to active lupus.

Conclusions In this cohort, nephritis and recent prednisone dose $>11 \mathrm{mg} /$ day were significant risk factors for disseminated TB which is associated with poor prognosis.

\section{SERUM TUMOURTUMOR NECROSIS (TNF)-LIKE WEAK INDUCER OF APOPTOSIS (TWEAK) AND LEPTIN AS BIOMARKERS OF ACCELERATED ATHEROSCLEROSIS IN PATIENTS WITH SYSTEMIC LUPUS ERYTHEMATOSUS AND ANTIPHOSPHOLIPID SYNDROME}

${ }^{1} \mathrm{E}$ Mostafa*${ }^{*}{ }^{2} \mathrm{~A}$ badawi. ${ }^{1}$ Cairo, Egypt; ${ }^{2}$ kasr alainy university, internal medicinerheumatology and immunology, cairo, Egypt

\subsection{6/lupus-2017-000215.185}

Background and aims Patients with systemic lupus erythematosus (SLE) and antiphospholipidsyndrome (APS) are at increased risk of atherosclerosis, and occurs much earlier compared to the general population even after accounting for traditional risk factors. Aim of the work: To examine the association between serum TWEAK, leptin and subclinical atherosclerosis in SLE and APS.

Patients and methods Serum tumour necrosis factor (TNF)-like weak inducer of apoptosis(TWEAK) and leptin were measured in 30 SLE patients, 26 SLE patients with secondary APS(SLEAPS), 14 with primary APS (pAPS) and 20 age and sex matched control. The SLE diseaseactivity index (SLEDAI) was assessed in SLE patients. The intima media thickness (IMT) was measuredby carotid ultrasound.

Results Serum TWEAK was significantly higher in patients with pAPS $(945.1 \pm 16.2 \mathrm{pg} / \mathrm{ml})$ than in SLE-APS $(755.3$ $\pm 59.9 \mathrm{pg} / \mathrm{ml})$, SLE patients $(499.2 \pm 47.1 \mathrm{pg} / \mathrm{ml})$ and control $(129.6 \pm 18.6 \mathrm{pg} / \mathrm{ml}) \quad(\mathrm{p}<0.001)$. Also, serum leptin was significantly higher in pAPSpatients $(14.0 \pm 2.8 \mathrm{ng} / \mathrm{ml})$ compared to that in SLE-APS $(6.5 \pm 0.9 \mathrm{ng} / \mathrm{ml})$, SLE patients $(3.8 \pm 1.2 \mathrm{ng} /$ $\mathrm{ml})$ and control $(1.6 \pm 0.6 \mathrm{ng} / \mathrm{ml})(\mathrm{p}<0.001)$. The IMT was significantly increasedin the pAPS patients compared to SLE-APS group $(p<0.001)$, SLE patients $(p=0.006)$ and to the control $(p<0.001)$. A significant correlation was found between TWEAK with the body massindex and high density lipoprotein in SLE-APS and inversely with the random blood sugar and thediastolic blood pressure in SLE patients. Serum leptin only significantly correlated with the totalleucocytic count in SLE patients.

Conclusions Patients with pAPS are more liable to develop premature atherosclerosis even in theabsence of the traditional risk factors.

\section{FERROKINETICS IN ANAEMIAANEMIA OF CHRONIC DISEASE ASSOCIATED WITH SYSTEMIC LUPUS ERYTHEMATOSUS AND IRON DEFICIENCY ANAEMIA}

E Mostafa. Cairo, Egypt

\subsection{6/lupus-2017-000215.186}

Background and aims Systemic lupus erythematosus is a common autoimmune disease occurring predominantly in women. Anaemia is common in SLE patients, the most commom cause of anaemia is anaemia of chronic disease. The key mediator of anaemia of chronic disease is Hepcidin.

The aim of this study was to determine the role of hepcidin in anaemia of chronic disease in SLE and its role in differentiation between ACD and IDA.

Methods The study was conducted on 50 patients with SLE (25 patient with ACD and 25 patient without anaemia), 20 patients with iron deficiency anaemia (IDA) and 15 healthy controls. All study persons underwent full clinical assessment, CBC, ESR, serum iron, TIBC, ferritin and hepcidin measured by ELISA.

Results Serum hepcidin was significantly higher in SLE group than IDA than control groups, with mean+SD in SLE group $(7.8 \pm 3.4 \mathrm{mg} / \mathrm{dl})$ compared to mean $+\mathrm{SD}(4.6 \pm 2.5 \mathrm{mg} / \mathrm{dl})$ in IDA group and mean $+\mathrm{SD}(2.2 \pm 0.8)$ in the control group with $\mathrm{P}$ value $<0.001$, with sensitivity $75 \%$ and specificity $60 \%$ in detection of anaemia in general and with sensitivity $91 \%$ and specificity $67 \%$ in anaemia in SLE patients. Serum hepcidin was also significantly higher in SLE+a patients than SLEa, with mean + SD in SLE+a group $(9.6 \pm 3.5 \mathrm{mg} / \mathrm{dl})$ compared to mean $+\mathrm{SD}$ in SLE-a group $(5.6 \pm 2.8 \mathrm{mg} / \mathrm{dl})$ with $P$ value $<0.001$.

Conclusions The measurement of serum hepcidin is a useful lmarker for diagnosis of ACD in patients with SLE and its differentiation from IDA.

Serum hepcidin is both sensitive and specific for detection of anaemia in SLE patients, and is a useful marker for disease activity.

\section{PREVALENCE OF METABOLIC SYNDROME (MS) IN PATIENTS WITH SYSTEMIC LUPUS ERYTHEMATOSUS (SLE) IN MEXICAN POPULATION AND ITS RELATIONSHIP WITH INFLAMMATION MARKERS. MULTICENTER STUDY}

\footnotetext{
${ }^{1} S$ Muñoz López*, 'L Andrade Ortega, ${ }^{1} \mathrm{~F}$ Irazoque Palazuelos, ${ }^{2} \mathrm{D}$ Alonso Martínez, ${ }^{3}$ S. Hernández Sandoval, ${ }^{4}$ RÁ Galaviz Pérez, ${ }^{4} V$ Alvarado Romano, ${ }^{1} V M$ Rosales Don Pablo. ${ }^{1}$ Centro Médico Nacional 20 de Noviembre ISSSTE, Reumatology, Ciudad de México, Mexico; ${ }^{2}$ Hospital General Naval de Alta Especialidad, Internal Medicine, Ciudad de México, Mexico; ${ }^{3}$ Instituto Nacional de Cardiología Ignacio Chávez, Nuclear Cardiology, Ciudad de México, Mexico; ${ }^{4}$ Hospital General Naval de Alta Especialidad, Reumatology, Ciudad de México, Mexico
}

\subsection{6/lupus-2017-000215.187}

Background and aims Prevalence of MS is higher in patients with SLE than in the general population (16\%-32\%). Inflammatory activity and steroids have been associated with the SM. $25 \%$ of deaths from SLE have a cardiovascular (CV) origin and are associated with dyslipidemia, elevated BMI, insulin resistance and hypertension.

Objective To determine the prevalence of MS in Mexicans patients with SLE and its association with disease characteristics and inflammatory markers. 
Methods Cross-sectional study of patients with SLE. Demographics, coronary risk, disease activity and inflammatory markers were studied. The diagnosis of MS was established with the NHLBI/AHA criteria. Statistical analysis was performed using SPSS 20.0 software and a $\mathrm{P}$ value $<0.05$ was considered significant.

Results 126 patients with SLE, 107 women (84\%) and 19 men (15\%), age $41 \pm 13$ years old and disease duration $9 \pm 7$ years. The prevalence of MS was 33.3\%. No association was found with age, education level, smoking or steroid use in patients with MS. In multivariate analysis only elevated erythrocyte sedimentation rate (ESR) had a statistical significance $(p=0.012)$. Positive association was found between higher values of ESR and hypertriglyceridemia $(p=0.0002)$, body mass index $(p=0.0043)$ and lower levels of HDL and C3 $(\mathrm{p}=0.0152)$.

Conclusions The prevalence of MS in our population (33\%) was higher than reported in the SLICC registry (15\%). The association of metabolic and inflammatory characteristics increases cardiovascular risk by a proinflamatory state. The results suggest the need for early diagnosis and treatment of MS to reduce cardiovascular comorbidity in patients with SLE.

\section{VITAMIN D DEFICIENCY AS NOVEL RISK FACTOR OF ACCELERATED ATHEROSCLEROSIS CARDIOASCULAR DISEASES IN PATIENTS WITH SYSTEMIC LUPUS ERYTHEMATOSUS}

${ }^{1}$ RA Nugraha, ${ }^{1} F F$ Alkaff, ${ }^{1} \mathrm{M}$ Jonatan, ${ }^{1}$ RB Wicaksono, ${ }^{1} \mathrm{TN}$ Octora, ${ }^{2} \mathrm{R}$ Yudiwati, ${ }^{3} \mathrm{~A}$ Awalia. ${ }^{1}$ Faculty of Medicine Universitas Airlangga, Medicine, Surabaya, Indonesia; ${ }^{2}$ Faculty of Medicine Universitas Airlangga, Biomedics and Biomolecular Medicine, Surabaya, Indonesia; ${ }^{3}$ Faculty of Medicine Universitas Airlangga, Rheumatology, Surabaya, Indonesia

\subsection{6/lupus-2017-000215.188}

Background and aims Vitamin D deficiency is common in women living near to equatorial line. Deficiency of vitamin D could lead to more severe manifestation of autoimmune disease, it may accelerate complication in atherosclerosis cardiovascular disease.
Objective We aimed to evaluate the impact of vitamin D deficiency in the severity of SLE, especially in the appearance of ASCVD in SLE patients.

Methods Design: Systematic review and meta-analysis.

Data Sources: Electronic databases (CENTRAL; Medline; Springerlink; Cochrane Database) were searched up to May 2015.

Review methods: Longitudinal study that compared level of serum vitamin D in SLE patients with and without ASCVD manifestation were included. Study selection, data extraction and risk of bias assessment (Cochrane risk of bias tool) were performed by five reviewers.

Results Total of 16 trials (1723 participants) were included. Meta-analysis of 8 trials (781 participants) found that serum vitamin D (25-hydroxyvitamin D) levels in severe SLE patients with ASCVD manifestation were significantly lower compared to non-ASCVD SLE patients during remission (pooled RR $0.64 ; 95 \% \mathrm{CI}=0.34-0.77 ; \mathrm{p}=0.005)$. No statistically significant difference in serum vitamin $\mathrm{D}$ were observed in metaanalysis of other 8 trials (pooled RR 0.96; 95\% CI=0.54-1.7; $\mathrm{p}=0.12$ ). Moreover, there is a significant inverse correlation between serum vitamin D levels and Systemic Lupus Erythematosus Disease Activity Index $2000(r=-0.373, \mathrm{p}=0.016)$.

Conclusions Results demonstrates that vitamin D deficiency could be a novel risk factor for accelerating endothelial dysfunction and ASCVD in SLE patients. Vitamin D supplementation might modulate an immunosuppressive effects, endothelial repair mechanisms, and endothelial function in SLE patients with significant ASCVD risk.

\section{IMPACT OF DISEASE ACTIVITY ON ORGAN DAMAGE RISK OVER TIME IN SYSTEMIC LUPUS ERYTHEMATOSUS (SLE) -THE HOPKINS LUPUS COHORT}

${ }^{1}$ RT Burge, ${ }^{1} Z$ Xiang, ${ }^{1} \mathrm{~J}$ Paik, ${ }^{2} Y$ Wang, ${ }^{3} \mathrm{~L}$ Magder, ${ }^{4} \mathrm{M}$ Petri ${ }^{*}$. 'Eli Lilly and Company, GPORWE, Indianapolis, USA; ${ }^{2}$ Eli Lilly and Company, GSS, Indianapolis, USA; ${ }^{3}$ University of Maryland School of Medicine, Epidemiology and Public Health, Baltimore MD, USA; ${ }^{4}$ The John Hopkins University School of Medicine, Rheumatology, Baltimore- MD, USA

10.1136/lupus-2017-000215.189

Abstract 189 Table 1 Time-dependent cox proportional hazard models: effect of disease activity on the risk of new organ damage.

\begin{tabular}{|c|c|c|c|c|c|c|}
\hline \multirow[b]{2}{*}{ Variable } & \multicolumn{2}{|c|}{ Model 1} & \multicolumn{2}{|c|}{ Model 2} & \multicolumn{2}{|c|}{ Model 3} \\
\hline & HR $(95 \%$ CI) & P-value & HR $(95 \%$ CI) & P-value & HR $(95 \%$ CI) & P-value \\
\hline Age at cohort entry & $1.03(1.03-1.04)$ & $<0.001$ & $1.03(1.03-1.04)$ & $<0.001$ & $1.03(1.03-1.04)$ & $<0.001$ \\
\hline SDI score at cohort entry & $1.06(1.02-1.11)$ & 0.002 & $1.07(1.03-1.11)$ & $<0.001$ & $1.07(1.03-1.11)$ & $<0.001$ \\
\hline Immunosuppressant use during follow-up & $1.23(1.05-1.43)$ & 0.012 & $1.15(0.99-1.35)$ & 0.076 & $1.15(0.98-1.35)$ & 0.079 \\
\hline $\begin{array}{l}\text { Average corticosteroid use ( } \geqslant 7.5 \mathrm{mg} \text { vs. } \\
<7.5 \mathrm{mg})\end{array}$ & $1.74(1.49-2.04)$ & $<0.001$ & $1.61(1.37-1.89)$ & $<0.001$ & $1.61(1.37 .1 .89)$ & $<0.001$ \\
\hline $\begin{array}{l}\text { SELENA-SLEDAI score during follow- } \\
\text { up }(\geqslant 6 \mathrm{vs},<6)\end{array}$ & $1.40(1.17-1.67)$ & 0.012 & $0.82(0.65-1.03)$ & 0.088 & NA & \\
\hline $\begin{array}{l}\text { Proportion of clinic visits with SLEDAI } \\
\text { score } \geqslant 6 \text { during follow-up }\end{array}$ & NA & & $3.82(2.71-5.39)$ & $<0.001$ & $3.14(2.42-4.08)$ & $<0.001$ \\
\hline
\end{tabular}

